ÉGYPTE

monde arabe

\section{Égypte/Monde arabe}

$10 \mid 2013$

Les élections de la révolution (2011-2012)

\title{
Entre le savant et le politique : la campagne électorale de 'Amr Hamzâwî dans les élections législatives égyptiennes de l'automne 2011
}

\section{Giedre Sabaseviciute}

\section{(2) OpenEdition}

Journals

Édition électronique

URL : https://journals.openedition.org/ema/3186

DOI : $10.4000 /$ ema.3186

ISSN : 2090-7273

Éditeur

CEDEJ - Centre d'études et de documentation économiques juridiques et sociales

Édition imprimée

Pagination : 231-252

ISBN : 978-2-905838-81-0

ISSN : $1110-5097$

Référence électronique

Giedre Sabaseviciute, «Entre le savant et le politique : la campagne électorale de 'Amr Hamzâwî dans les élections législatives égyptiennes de l'automne 2011 », Égypte/Monde arabe [En ligne], 10 | 2013, mis en ligne le 10 février 2014, consulté le 07 juillet 2022. URL : http://journals.openedition.org/ema/ 3186 ; DOI : https://doi.org/10.4000/ema.3186

Ce document a été généré automatiquement le 7 juillet 2022

Tous droits réservés 


\title{
Entre le savant et le politique : la campagne électorale de 'Amr Hamzâwî dans les élections législatives égyptiennes de l'automne 2011
}

\author{
Giedre Sabaseviciute
}

1 Le présent article est consacré à l'étude de la campagne électorale organisée par 'Amr Hamzâwî, chercheur et professeur en science politique, dans le cadre de sa candidature aux élections législatives, lancées en novembre 2011 pour élire le premier Parlement égyptien après la démission de Moubarak. Candidat dans la $4^{\mathrm{e}}$ circonscription électorale, incluant les quartiers résidentiels de Héliopolis, Al-Nuzha, Madînat AlChurûq et Madînat Badr, Hamzâwî a réussi à remporter une victoire écrasante avec $53,75 \%$ de voix recueillies au premier tour, battant ainsi son principal rival, Muhammad Abu Al-'Azm, candidat du parti de la Liberté et de la Justice, bras politique des Frères musulmans. Et pourtant, au premier abord, la victoire de Hamzâwî s'annonçait difficile. Libéral occidentalisé, détenteur d'une double nationalité égyptienne et allemande, résidant de longue date à l'étranger, fiancé à une femme du milieu artistique, se prononçant sur des sujets tabous, dépourvu d'appuis locaux dans sa circonscription électorale et, d'une manière générale, dépourvu d'expérience politique, 'Amr Hamzâwî réunissait autant d'attributs considérés comme disqualifiants dans le jeu politique égyptien. Qualifiée de «blague » par les vétérans de la politique tels que feu Tal'at Al-Sâdât ${ }^{1}$, la candidature de Hamzâwî a fait l'objet de nombreuses campagnes de diffamation tout au long de sa campagne électorale.

2 Cependant, au lieu de me préoccuper d'analyser globalement les raisons de sa victoire électorale, je souhaite ici porter l'attention sur les stratégies d'argumentation et les types de légitimation politique qu'il a mobilisées dans sa campagne, afin de justifier sa vocation à se présenter. Je m'interrogerai sur les manières dont il a joué sur différents 
registres de présentation de soi, alternativement puisés dans sa notoriété médiatique et son identité d'universitaire libéral, tout en prenant en considération la configuration politique égyptienne nouvelle créée par la démission de Moubarak, qui a favorisé sa victoire. On verra comment, en fin de compte, en recourant à diverses stratégies argumentatives et symboliques, Hamzâwî a réussi à convertir en atouts puissants des attributs perçus comme des handicaps dans la compétition électorale. Le cas de 'Amr Hamzâwî est instructif dans la mesure où il reflète des mutations dans les pratiques électorales en Égypte: des stratégies électorales autrefois inconcevables ont obtenu lors de ce scrutin un succès écrasant et inattendu. À partir d'un corpus constitué par l'étude ethnographique de sa campagne sur le terrain à Héliopolis, des entretiens réalisés avec les volontaires engagées dans cette campagne, du décryptage de ses discours lors de ses apparitions publiques - conférences et talk-shows politiques - et de l'analyse de ses articles publiés dans les quotidiens Al-Churûq et Al-Masrî Al-Yawm, je tenterai de mettre à jour les différents répertoires de mobilisation électorale du candidat Hamzâwî.

\section{Le peoplisation de la compétition politique à l'heure de I'hégémonie médiatique}

\section{La reconfiguration de la scène médiatique égyptienne}

3 Avant de passer aux modalités de la construction de la notoriété médiatique de 'Amr Hamzâwî, il convient de donner un aperçu rapide de la recomposition de la scène médiatique égyptienne après la chute de Hosni Moubarak en février 2011. En se positionnant contre le mouvement de protestation à ses débuts, les médias gouvernementaux - audiovisuels et presse écrite -, se sont condamnés au discrédit, conduisant ainsi à un renversement des positions de pouvoir au sein du champ médiatique $^{2}$. Si, au début du mouvement de protestation, ce furent principalement les chaînes satellitaires panarabes, comme Al-Jazîra et BBC Arabic, qui assurèrent la couverture des événements de Tahrîr, après la démission de Moubarak en revanche, les chaînes de télévision locales ont tenté de reprendre le relais pour s'imposer comme "les médias de la révolution ». En l'occurrence, certaines chaînes privées ont gagné la confiance des manifestants après avoir réussi, à travers des débats télévisés, à influer directement le cours des événements de Tahrîr. Pour rappeler les épisodes les plus marquants, ce sont les larmes de l'activiste Waël Ghoneim versées en direct lors du talkshow « Dix heures du soir » (al-'âchira' masâ'an) sur Dream Two qui auraient relancé, le 7 février, un mouvement de protestation alors en voie d'essoufflement. De même, la confrontation, le 2 mars, entre le romancier 'Alâ' Al-Aswânî et le Premier ministre Ahmad Chafîq, dans l'émission télévisée « Notre pays en Égyptien » (baladnâ bi-l-masrî) sur ONTV a conduit Ahmad Chafîq à annoncer sa démission le lendemain. De plus, en consacrant une série de débats sur le rôle néfaste de la télévision officielle dans la révolution du 25 janvier, les chaînes privées ont cherché à montrer qu'elles étaient plus objectives et plus proches du mouvement de contestation ${ }^{3}$.

Afin de rassurer la société sur sa loyauté à l'égard de la révolution, le Conseil suprême des forces armées (CSFA) - aux commandes du pays immédiatement après la chute de Moubarak -, a entrepris une relative libéralisation du marché privé de l'audiovisuel. À côté des acteurs bien établis comme Dream TV, ONTV, Mihwar TV, Hayât TV, le marché a 
accueilli seize nouveaux entrants, parmi lesquels les chaînes Tahrîr, Al-Bayt Baytak, Modern Huriya, Egypt $25^{4}$. Ces chaînes ont réussi à séduire de larges pans de l'audience grâce aux talk-shows, format privilégié de l'émission politique en Égypte. Le recours aux talk-shows a offert le moyen de contourner l'interdiction faite aux chaînes privées de diffuser des bulletins d'information politiques - activité réservée aux chaînes gouvernementales. En devenant la seule source crédible d'information aux yeux de l'opinion contestataire, les médias privés ont acquis une influence considérable. Cette influence s'est notamment mesurée dans leur capacité à promouvoir les nouvelles élites politiques et intellectuelles de l'ère révolutionnaire. Les chaînes privées ont agi sur la définition de l'agenda politique et donné une tribune médiatique aux figures intellectuelles et politiques constamment invitées sur les plateaux télévisés. En fournissant un accès à la sphère de la discussion publique à ces heureux élus, elles ont directement contribué à accroître leur visibilité auprès d'un public en quête de nouvelles autorités intellectuelles. On pourrait même aller plus loin et suggérer que c'est la télévision privée qui a produit "les leaders de la révolution", et cela en l'absence de leadership révolutionnaire clairement identifié ${ }^{5}$.

5 À côté des médias audiovisuels, les pages d'opinion de la presse dite indépendante, à l'avant-garde desquelles se situent les quotidiens Al-Masrî Al-Yawm, Al-Churûq et AlDustûr, ont joué un rôle comparable. Dès le déclenchement de la contestation, les lecteurs ont porté un intérêt particulier à la rubrique "opinion" pour pouvoir s'orienter dans la nouvelle configuration politique à l'aide des analyses fournies par les intellectuels ${ }^{6}$. À titre d'exemple, la page "opinion » d'Al-Churûq a accueilli, en févriermars 2011, trente-deux nouveaux contributeurs, dont une partie étaient des anciens contributeurs qui, inspirés par la chute de Moubarak, ont de nouveau repris la plume ${ }^{7}$. Écrire dans Al-Churûq en ce moment historique était incontestablement le meilleur moyen de se faire entendre et d'affirmer une position par rapport aux événements en cours. Dans une Égypte post-Moubarak obsédée par la chasse aux "rescapés » de l'ancien régime (fulûl), la valeur de l'intellectuel a fini par se mesurer à son degré d'intégrité révolutionnaire. Par conséquent, les pages «opinion» de la presse indépendante sont devenues l'espace idéal pour affirmer sa fidélité aux valeurs de la révolution, pour justifier ses décisions politiques ou corriger une réputation souillée par des prises de positions antérieures ou des liens avec le système Moubarak ${ }^{8}$. Les figures issues de diverses sphères d'activités, les professionnels des médias (Yusrî Fûda, Lâmîs Al-Hadîlî), les écrivains (Khâlid Al-Khamîsî, Bahâ' Tâhir), les universitaires (Mu'taz Abdullâh, 'Amr Chûbakî), les blogueurs ('Ala' 'Abd-al-Fatâh, Tâmir Muwâfî), les hommes politiques ('Alî Al-Silmî) et les religieux (Anbâ Mûsâ, 'Ali Gum'a') ont trouvé dans les pages-débats le moyen de faire connaître leurs opinions et de s'imposer comme les références intellectuelles de la période.

6 L'interpénétration des milieux journalistiques et intellectuels constitue, certes, une caractéristique permanente du champ intellectuel égyptien, les médias offrant aux intellectuels de nombreux débouchés leur permettant de toucher un public plus étendu que celui de l'écrit. Néanmoins, avec l'explosion du marché des talk-shows, et grâce à de nombreuses passerelles entre les plateaux télévisés et la presse écrite, les professionnels des médias, les hommes politiques, les activistes de la société civile et même les hommes d'affaires propriétaires de chaînes télévisées se sont posés en «faiseurs d'opinion » pour prétendre au statut prestigieux d'« intellectuels ». À l'heure où les personnalités publiques ayant un accès privilégié aux médias s'autorisent de plus en plus à intervenir sur des questions publiques, les frontières entre le champ 
journalistique et intellectuel se brouillent: des personnalités publiques se retrouvent sur un banc d'invités dans tel ou tel talk-show; elles sont animatrices de telle autre émission, et contributrices dans la page « opinion » des grands quotidiens égyptiens.

\section{La construction de la notoriété médiatique de ‘Amr Hamzâwî}

7 La construction de la notoriété médiatique de 'Amr Hamzâwî semble suivre le schéma décrit précédemment: succès académique à l'étranger, notoriété dans les médias internationaux, passage par la page "opinion» des grands quotidiens indépendants égyptiens - et, enfin, lancement d'un talk-show personnalisé, qui, en assurant un accès à une large audience, constitue le comble de la visibilité, et par là même, de l'influence de l'intellectuel.

8 Né au Caire en 1967, 'Amr Hamzâwî s'est forgé sa renommée académique en Europe. Diplômé en science politique de l'Université du Caire en 1988, il voyage à la Haye, aux Pays-Bas, pour y faire son Master. Il en obtient deux, l'un à l'Institut des Sciences Sociales à la Haye, le second à l'Université d'Amsterdam. Hamzâwî se déplace ensuite à Berlin, où il obtient un doctorat en science politique à l'Université Libre de Berlin en 2002. Il se marie en Allemagne et devient père de deux enfants. Recruté au sein d'un think tank américain, la Fondation Carnegie pour la paix internationale en 2005, 'Amr Hamzâwî est nommé en 2008 directeur de recherche au Carnegie Middle East Center à Beyrouth, poste qu'il occupera jusqu'en 2010. C'est au sein de la Fondation que Hamzâwî, spécialisé dans le processus de démocratisation au Moyen-Orient et le rôle des mouvements islamistes, se construit la réputation d'un héraut de la démocratie et d'un expert en matière de transition démocratique. Dans le cadre de ses fonctions à Carnegie, Hamzâwî écrit plusieurs rapports dénonçant le verrouillage du système politique égyptien, les campagnes systématiques d'intimidation des Frères musulmans et l'institutionnalisation de la transmission héréditaire du pouvoir par les amendements constitutionnels de 2007. Ces publications lui ont valu une contreattaque immédiate dans la presse gouvernementale : il s'est vu accusé de ternir l'image de l'Égypte à l'étranger, de servir de relais entre les Frères musulmans et l'administration américaine ${ }^{9}$, d'avoir échangé sa nationalité égyptienne contre la nationalité allemande et de suivre la voie d'un autre intellectuel "vendu à l'étranger ", Sa'd Al-Dîn Ibrâhîm ${ }^{10}$. À la suite de cette campagne de presse, la personne de Hamzâwî suscita l'intérêt des services de sécurité. Des agents se seraient rendus à l'université du Caire pour s'enquérir de la date de son retour - un avertissement qui poussa Hamzâwî à annuler son intervention au sein d'une conférence organisée par la bibliothèque d'Alexandrie. Il renonça à se rendre en Égypte pendant la période 2007-2008 ${ }^{11}$. Ainsi, Hamzâwî s'est construit la réputation d'un intellectuel critique du régime de Moubarak, intégré dans des cercles académiques, et dépourvu de toute ambition politique. Néanmoins, ce capital accumulé à l'étranger constitua aussi le point majeur de la vulnérabilité de sa candidature, offrant à ses détracteurs l'occasion de lui lancer deux types d'accusations: la méconnaissance de l'Égypte, d'une part, et l'action au service des intérêts étrangers, d'autre part. À l'ère du soupçon et de la prolifération des théories du complot, la carrière à l'étranger de Hamzâwî n'a pas manqué de faire naître rumeurs et accusations, contraignant celui-ci à déployer des stratégies d'argumentation et de légitimation afin de convertir ce handicap en atout. 
Dès l'année 2006, 'Amr Hamzâwî commença à gagner en notoriété dans les médias internationaux grâce à ses interventions fréquentes à titre d'expert en politique égyptienne dans les émissions diffusées par les chaînes satellitaires panarabes Al-Jazîra et $B B C$ Arabic, ainsi que par ses articles d'opinion bimensuels publiés dans le quotidien Al-Hayât. Pendant l'été 2010, Hamzâwî s'investit sur la scène intellectuelle égyptienne avec des contributions quotidiennes dans la page d'opinion d'Al-Churûq, qu'il transforme après le déclenchement du mouvement de protestation, en courts commentaires sur la situation intitulés « De la place Tahrîr ». Après la démission de Moubarak, Hamzâwî s'associe à plusieurs initiatives lancées par les intellectuels en vue de créer une instance susceptible de jouer un rôle d'interlocuteur auprès du CSFA et de formuler une stratégie de transition politique « sécurisée $~^{12}$. Enfin, il se voit proposer par le Premier ministre d'alors, Ahmad Chafîq, le poste de ministre de la Jeunesse offre qu'il refuse. Depuis lors, la personne de 'Amr Hamzâwî devient omniprésente dans l'espace public : il évolue d'un talk-show à un autre, d'une table-ronde à une conférence, et participe à des initiatives politiques sans lendemains. Bref, il s'investit pleinement dans les nouveaux réseaux de sociabilité des intellectuels. Réputé pour son éloquence, son charisme et son contact facile - qualités recherchées par les médias -, mais aussi pour sa rigueur et la pertinence de ses analyses politiques, Hamzâwî est sollicité aussi bien par les chaînes télévisées que par les organisateurs de conférences académiques. Enfin, au début du mois de septembre 2011, Hamzâwî lance son propre programme de talk-show, « Discussion égyptienne » (Kalâm misrî) sur CBC, qu'il arrête au bout de sept émissions pour «ne pas transformer l'émission en outil de propagande au service de sa candidature ».

Sur fond de surexposition médiatique, la révélation publique de sa liaison avec l'actrice et chanteuse Basmâ Ahmad Darwîch, après l'attaque de leur véhicule par des malfaiteurs dans une banlieue cairote en plein mois de Ramadan, poussa Hamzâwî à jouer la carte du people. Si, au début, il nia catégoriquement l'existence de la liaison, la relation fut reconnue après la publication, dans le quotidien Al-Churûq, d'un plaidoyer de l'intéressé pour la « liberté personnelle de choisir l'objet de son amour, quelles que soient ses origines ou le milieu professionnel dont il est issu ${ }^{13}$ ». Écrit dans un langage sincère et touchant, l'article a été inévitablement lu comme une déclaration d'amour à « la reine de son cœur », Basmâ. Au lendemain de la parution de l'article, l'événement fut au centre des discussions des talk-shows, des articles de presse, des réseaux sociaux, alors que sur Youtube se multipliaient les chansons composées à la gloire de Hamzâwî et de Basmâ ${ }^{14}$. Il devint ainsi un héros romantique auprès d'une partie de la jeunesse égyptienne, si bien que ses détracteurs eurent du mal à trouver des contre-arguments sans tomber dans un conservatisme vieille école. Le couple n'hésita plus à s'afficher ensemble en public dans les marches de protestation, les plateaux télévisés et même dans le cadre des tournées électorales à Héliopolis, étant sûrs d'attirer des foules de jeunes séduits par l'opportunité d'assister à une histoire d'amour en direct.

11 Cette mise en scène de la vie privée permit à Hamzâwî de conforter son identité libérale. En défendant la liberté amoureuse, Hamzâwî parvint à transformer son histoire personnelle en acte politique. En définitive, il réussit à s'imposer dans les milieux politiques comme une personnalité controversée, courageuse et prête à défier les conventions sociales, au nom d'une vision politiquement libérale de la société. 


\section{La campagne sur le terrain}

12 «Un nouveau commencement pour la nouvelle Égypte " (bidâya jadîda li-misr jadîda), c'est avec ce slogan conçu à travers un jeu de mots - la nouvelle Égypte étant le nom arabe de Héliopolis - que Hamzâwî débarqua sur le terrain de la compétition électorale. S'insérant parfaitement dans les priorités de l'Égypte de l'après Moubarak, le thème de la rupture constituait l'axe majeur de sa campagne. Il chercha à incarner la rupture aussi bien par le choix des supports matériels de sa campagne que dans les stratégies argumentatives déployées pour justifier sa candidature. Cette volonté de rupture se révèle notamment dans son refus explicite d'incarner le rôle du député tel qu'il était conçu traditionnellement chez les électeurs égyptiens. Ce rôle traditionnel s'incarne dans quatre registres du pouvoir: le pouvoir politique, fondé sur la proximité du candidat à l'État et sur sa capacité à fournir des services à ses électeurs; le pouvoir financier, garantissant la prédisposition du candidat à apporter un secours matériel aux pauvres; le pouvoir familial, s'appuyant sur la logique de l'ancrage local et de la proximité du candidat et de sa famille avec les électeurs de la circonscription; et le pouvoir religieux, grâce auquel le candidat dispose d'une légitimité à représenter ses mandants en tant que groupe confessionnel ${ }^{15}$.

Dans les élections précédentes, le critère essentiel de la légitimité du candidat se fondait sur les relations que ce dernier entretenait avec l'État. Le succès électoral était conditionné par la capacité du candidat à mobiliser ses réseaux personnels pour offrir des services aux habitants. La figure du notable local, proche des cercles du pouvoir et disposant d'un bilan solide en matière d'action sociale, médicale et éducative, traduisait l'idéal-type du candidat vainqueur ${ }^{16}$. Avec la chute de Moubarak, c'est la légitimité révolutionnaire qui devient la ressource principale des candidats - fondée, elle, sur leur distance critique avec l'ancien régime. Cette nouvelle configuration politique a permis à Hamzâwî de construire son discours électoral sur le refus de la figure du député "pourvoyeur de services». Il fait ainsi de nécessité vertu. Il n'était pas issu de Héliopolis et il ne disposait pas d'appuis locaux dans cette circonscription. Ce qui pouvait apparaître comme un handicap dans la compétition électorale a donc été transformé en atout. Le candidat s'est ainsi lancé dans la critique d'une représentation politique fondée sur les "circonscriptions naturelles" (dâ'ira tabî̀iya) établies en fonction de critères démographiques, sociologiques et historiques. D’après Hamzâwî, cette forme de représentation encourage les candidats à s'appuyer sur leurs réseaux locaux de solidarité, favorisant ainsi le clientélisme. Il explique que sa décision de se présenter pour le siège individuel d'Héliopolis se fonde "sur un choix conscient ». Se refusant à exploiter « des relations personnelles ou familiales ou une présence sur le terrain », il promeut la vision "d'un programme électoral et d'un projet politique ». Selon lui, « la logique de la circonscription naturelle a produit les parlements les plus corrompus en Égypte : les parlements des “députés de services"(nuwâb al-khidma) qui fournissaient des services à un nombre restreint d'habitants, des parlements minés par le favoritisme et la corruption rampante, et cela tout au long des vingt dernières années! $\gg{ }^{17}$. Il souligne aussi au cours de sa campagne que le candidat aux législatives n'est pas un candidat local mais le candidat de toute la nation (nâ'ib al-umma), chargé d'œuvrer au bien-être de l'ensemble des habitants de sa circonscription par le biais du travail législatif au Parlement. «Dans les législatives, il faut rompre avec la logique de la circonscription naturelle $»^{18}$, conclut-il. 

Hamzâwî à Héliopolis a été faite pour conforter cette image de "candidat de la nation ». Si, à l'instar de la majorité des programmes présentés, celui de Hamzâwî comportait deux volets, national et local, les priorités nationales dominaient. Arrêtonsnous tout d'abord sur ses engagements au niveau local. D'une manière générale, Hamzâwî insiste sur trois dossiers : le problème des embouteillages, de la propreté et de la préservation d'un héritage architectural qui a fait la réputation d'Héliopolis. Hamzâwî propose d'étendre la ligne de métro de Héliopolis pour le relier à Nuzha et d'organiser des campagnes de nettoyage et d'embellissement du quartier en partenariat avec des entreprises privées. Pour remédier à la situation des habitats les plus défavorisés, à Manchiyat Al-Bakrî, Mantiqat Al-Badr, Haykestep et Maydân AlGâmi', il convient, selon lui, de construire des écoles et des hôpitaux publics. Il faut aussi développer des centres pour la jeunesse et assurer une formation technique et industrielle afin de remédier au problème du chômage - tout cela en s'appuyant sur les initiatives privées, à travers les investissements d'hommes d'affaires locaux et de propriétaires d'usines ${ }^{19}$. Il convient de noter que cette volonté d'impliquer des hommes d'affaires dans son projet de développement visait à mobiliser les appuis locaux dont il était dépourvu. Cependant, malgré l'intérêt accordé aux préoccupations locales, ce sont surtout les problématiques nationales qui forment la base du message politique. Les nouveaux enjeux politiques de l'après Moubarak, liés à l'espoir de voir naître un nouvel ordre politique, orientent la sélection des thèmes: rédaction de la nouvelle Constitution, garantie de la laïcité de l'État, protection de l'État de droit et de l'égalité des droits des citoyens, lutte contre la discrimination, etc. C'est sur ces sujets que Hamzâwî a conduit son discours de mobilisation sur le terrain en donnant à ses conférences et à ses discours une visée éducative, incluant une pédagogie du libéralisme politique, des leçons sur les enjeux de l'acte électoral et de la participation politique, une explication de la mission du député au Parlement, du rôle des institutions dans un système démocratique et de la nécessité du dialogue avec les groupes islamistes. aussi dans sa manière de conduire la campagne sur le terrain. Il dénonce ainsi ce qu'il nomme «la propagande négative » caractérisée par le dénigrement systématique des candidats rivaux et l'arrachage de leurs affiches électorales ${ }^{20}$. Il fait signer aux candidats de la circonscription une "charte d'honneur " (mithâq al-charaf) en faveur d'une campagne honorable. Il se veut facilement accessible dans sa permanence de la place San Fatima à Héliopolis. Il promeut la transparence grâce à la diffusion quotidienne de courtes vidéos sur Youtube, dans lesquelles il raconte ses journées de campagne. Il marque aussi sa différence avec ses rivaux en ayant recours à un dispositif électoral plus discret que celui de ses concurrents. Des affiches simples, avec un papier plastifié au lieu des bannières traditionnelles en tissu, ont été suspendues en des points stratégiques de Héliopolis, sans sacrifier à la saturation du sur-affichage. De même, Hamzâwî a évité les processions bruyantes accompagnées de véhicules diffusant de la musique populaire, préférant clôturer sa campagne avec une tournée dans le quartier en bus panoramique. C'est sur ces ressources, coûteuses et inhabituelles, qu'a porté la critique de ses rivaux, qui l'ont accusé d'être « un riche venu de l'Allemagne ».

Toutefois, le choix d'Héliopolis s'explique en termes stratégiques: Héliopolis est la circonscription où le projet politique de Hamzâwî avait les plus fortes chances de 
mobiliser l'électorat. Deux facteurs ont particulièrement favorisé sa candidature : la composition socio-économique et confessionnelle de Héliopolis et le nouveau système de découpage des circonscriptions mis en place par le code électoral de septembre 2011. Outre Héliopolis, les quartiers qui composent la $4^{\mathrm{e}}$ circonscription - Madînat Badr, Madînat Al-Churûq et Al-Nuzha - sont des "villes nouvelles » situées en plein désert, qui accueillent majoritairement une population aisée. Par conséquent, l'insignifiance démographique des habitats présentant des besoins urgents de services (pour en mentionner quelques uns : Mantiqat Al-Badr, Haykestep, Maydân Al-Gâmi') a affaibli la pratique clientéliste de l'échange - "une voix contre un service». En outre, l'importante communauté chrétienne que compte Héliopolis semblait prédisposée à voter pour Hamzâwî, dans la mesure où son rival principal était le candidat islamiste du parti de la Liberté et de la Justice, bras politique des Frères musulmans, Muhammad Abû Al-'Azm. Pour ne pas risquer la dispersion des voix, il vallait mieux voter pour Hamzâwî que pour Muhammad Salâh, candidat des «Égyptien Libres ", parti fondé par l'homme d'affaires copte Nagîb Sâwîris, associé traditionnellement à l'électorat copte. À cet égard, l'importance accordée à la question copte par Hamzâwî dans son discours électoral n'est pas surprenante. Outre l'intérêt porté au problème de la discrimination à l'égard des coptes, et à leur exclusion du jeu politique, notamment dans ses articles publiés dans le quotidien Al-Churûq ${ }^{21}$, ce fut à la cathédrale Saint-Marc à 'Abâsiyya, et en présence d'évêques coptes, que Hamzâwî a annoncé, en mars 2011, la fondation du "parti Égyptien Démocratique et Socialiste » - parti auquel il s'associa mais dont il se retira ensuite. Sa participation à une chorale de Noël dans une église à Héliopolis acheva le processus d'auto-identification de l'électorat copte à la figure de Hamzâwî en créant une (utile) confusion sur ses liens supposés avec le parti des Égyptien Libres ${ }^{22}$.

Enfin, l'élargissement des circonscriptions provoqué par le nouveau découpage électoral (9 circonscriptions pour le gouvernorat du Caire) marginalise les notables locaux et favorise les personnalités connues au niveau national. Cette notoriété pouvait être acquise soit grâce aux médias, soit grâce à des ressources financières suffisantes pour se faire connaître à l'échelle d'une circonscription. C'est ici qu'intervient l'importance de l'exposition médiatique de 'Amr Hamzâwî : grâce à la télévision, il était déjà connu à Héliopolis bien avant le lancement de sa campagne électorale. Conscient de l'importance de son image construite par les médias, Hamzâwî exploita sa renommée médiatique. En se présentant sur le terrain accompagné de sa compagne Basmâ, il a réussi à transformer ses tournées électorales en un show, une sorte de spectacle, baigné dans une ambiance de fête et de bonne humeur, attirant une masse d'électeurs potentiels désireux de voir «en vrai » une vedette de la télévision. C'est également sa notoriété médiatique qui a permis à Hamzâwî de se passer d'ancrage local. La crédibilité politique acquise grâce à son activisme après le départ de Moubarak a été renforcée par les médias, qui lui ont conféré l'influence politique lui permettant de remporter la victoire électorale. C'est ainsi qu'en choisissant les personnalités dignes de participer à la discussion publique, les médias ont accompli un véritable travail d' " investiture » d'une nouvelle élite politique, à l'heure où les anciennes élites ont été délégitimées par la situation révolutionnaire. 


\section{Heurs et malheurs de l'universitaire en campagne électorale}

\section{Assurer l'intégrité révolutionnaire : le calvaire contre les rumeurs} employées pour justifier sa candidature et pour contrer deux types d'accusation qui lui étaient adressées : son caractère de «khawâga ${ }^{23}$ » lié à son séjour à l'étranger, consacré par l'acquisition de la nationalité allemande, et son parachutage sur la scène politique. La nouvelle configuration politique créée par la chute de Moubarak a fourni des arguments puissants pour contrer ce type d'accusation : la sphère politique ouverte par «la révolution du 25 janvier » était destinée à accueillir de nouveaux acteurs, en particulier ceux qui en avaient été exclus auparavant. "La révolution du 25 janvier » formait au moment des élections législatives la base de la légitimité de toute action politique - on avait du mal, en effet, à trouver des forces politiques actives se revendiquant explicitement du régime de Moubarak. Dès lors, les candidats ont fondé leur légitimité politique sur leur engagement dans le soulèvement populaire et leur distance à l'État comme gages de leur «intégrité révolutionnaire ». D'une manière générale, on peut garantir son "intégrité révolutionnaire " de deux façons : soit en mettant en avant une opposition au régime de Moubarak dans les années précédant sa chute, avec pour comble d'efficacité l'arrestation et le séjour en prison (sort subi par les intellectuels activistes du mouvement Kifâya et des militants Frères musulmans); soit en excipant d'une absence physique dans le pays pendant la période autoritaire, garante de l'immunité face à toute accusation de compromission politique. Les trajectoires de Muhammad Al-Barâd'î et de 'Amr Hamzâwî remplissent cette dernière condition. Il va sans dire que la première voie, comportant davantage de souffrances et de sacrifices, est porteuse de meilleures chances politiques. Hamzâwî a puisé dans les deux types d'argumentation : il s'est présenté comme un activiste, un opposant, en tant que tel sujet à la répression du régime, et comme un intellectuel ayant acquis à l'étranger le savoir et la compétence nécessaires pour la construction de «la nouvelle Égypte».

19 Le séjour à l'étranger est une arme à double tranchant : en fonction du public auquel on s'adresse, il peut constituer aussi bien un préjudice qu'un atout. Si l'éducation et l'expérience acquises à l'étranger confèrent au candidat une certaine couleur de modernité, rimant avec ouverture d'esprit et compétence, le séjour en dehors d'Égypte peut nourrir une accusation d'ignorance vis-à-vis des réalités de la société égyptienne. On devient coupable de préférer le confort de l'étranger au partage des souffrances du peuple, voire de trahir la patrie et d'être à la solde de l'étranger. Cette perception contradictoire est sans doute liée au rapport ambivalent "d'amour-haine» qu'entretient la société égyptienne avec ce qu'elle désigne comme l'Occident. En partant de ce constat, Hamzâwî a du jouer sur plusieurs facettes de sa biographie pour exposer les raisons de ses choix, afin d'agréger effectivement les groupes et les soutiens les plus divers.

Tout d'abord, Hamzâwî a insisté sur le fait que son départ en Europe avait été motivé par la quête d'un savoir et d'une compétence qu'il se promettait de mettre au service de l'Égypte. Le prix de l'exil n'a pas signifié la perte de contact avec les réalités égyptiennes, puisque Hamzâwî a souligné que son travail au sein de l'institut Carnegie, 
consacré au dossier égyptien, lui a permis d'acquérir une bonne connaissance de la situation politique de l'Égypte. De surcroît, il a acquis aux États-Unis une expertise en matière de transition démocratique. Dans un talk-show salafiste, " Misr Jadîda » (Nouvelle Égypte), Hamzâwî explique en ces termes les raisons de son départ d'Égypte à l'animateur de l'émission, la vedette salafiste Khâlid 'Abdallah: "Mon passage dans ces trois pays (Pays-Bas, Allemagne, États-Unis) était lié au travail académique qui portait continûment sur l'Égypte. Je me suis spécialisé dans la science politique, la philosophie politique, l'étude des transitions démocratiques. Tous mes articles ne concernent que l'Égypte (...). En toute honnêteté et objectivité, j'ai énormément profité de mon expérience à l'étranger. L'expérience académique et celle de la vie dans un nouveau contexte est bénéfique: (elle invite à l'ouverture des horizons et du regard. Et nous ne devons pas en avoir peur : je n'ai pas peur de regarder l'Autre (l'Occident), mais je dialogue avec lui et je profite de ses connaissances». En plus de lui avoir donné l'occasion de manifester l'existence d'un avantage, lié à son " ouverture à l'Autre " par rapport à son interlocuteur Khâlîd 'Abdallah, son séjour à l'étranger lui a permis également de se forger une réputation d'opposant au régime égyptien par l'exercice de la plume. C'est à cause de ses articles publiés par la Carnegie ou par la presse anglophone que Hamzâwî aurait été contraint à l'exil volontaire entre 2007 et 2008. Il possède ainsi un équivalent du séjour en prison sur la terre natale, ce qui renforce sa prétention révolutionnaire. Pour contrer l'accusation de "parachutage ", Hamzâwî rétorque qu'il a toujours été proche de l'Égypte à travers ses contributions dans les quotidiens Al-Masrî Al-Yawm et Al-Churûq ${ }^{24}$ et son expérience à la Carnegie, dont " peut s'enorgueillir chaque universitaire ${ }^{25}$ ». Et même si cela n'était pas le cas, «chaque citoyen égyptien a le droit de décider à tout moment de s'intéresser aux affaires publiques et politiques, et personne d'autre ne peut l'en priver sous prétexte de son absence dans la vie politique antérieure ». "La révolution n'est la propriété de personne ${ }^{26}$ ", tranche-t-il.

Revenant sans cesse dans les débats électoraux, l'affaire de la double nationalité de 'Amr Hamzâwî a constitué un véritable talon d'Achille. La décision prise pendant son séjour à Berlin de renoncer temporairement à sa nationalité d'origine pour accéder à la nationalité allemande a été mal perçue par une large partie de la société égyptienne, imprégnée d'un fort sentiment national. Parce qu'il n'était pas possible de transformer cet handicap en atout, Hamzâwî a été contraint de renoncer à sa nationalité allemande, décision qu'il annoncera le 17 novembre 2011, juste après l'ouverture officielle de la campagne électorale le 8 novembre. Les retards pris dans cette décision ne furent pas sans conséquence, et provoquèrent, dans un climat de rumeurs sur sa non-éligibilité au Parlement, le dépôt de nombreuses plaintes contre sa candidature ainsi que des demandes exprimées par les hommes politiques visant à interdire les porteurs de la double nationalité de se présenter aux élections ${ }^{27}$. Brandissant l'acte officiel du renoncement à la nationalité allemande dans ses apparitions publiques, Hamzâwî mena une véritable guerre contre ces rumeurs, qui mettaient en cause sa loyauté à l'égard de la patrie.

\section{Se servir de l'identité d'universitaire}

L'argumentation visant à exploiter la ressource universitaire s'est surtout déployée dans les contributions de Hamzâwî au journal Al-Churûq. Hamzâwî a mis en avant deux attributs associés à l'identité d'universitaire : sa qualité d'expert, de dépositaire d'un 
savoir technique sur les façons de mener une transition démocratique, d'une part, et sa qualité d'impartialité, permettant de créer une impression de distance à l'égard du jeu politique, d'autre part. Hamzâwî a converti un capital intellectuel accumulé à l'Université en capital politique. Ce transfert du savoir académique vers le champ politique s'exprima, tout d'abord par l'emploi dans ses articles d'Al-Churûq d'une langue savante tirée du lexique de la science politique. En se parant des atours de la science, et donc de la vérité, le discours savant a un effet social certain, conférant à celui qui le prononce «le monopole du point de vue légitime ${ }^{28}$ ». En employant le langage de la science politique, Hamzâwî se dota de l'autorité et de la légitimité pour "parler politique » à partir de sa position d'expert. Au langage s'ajoutèrent les idées politiques que Hamzâwî présenta sous la forme de "recommandations ». Il s'autorisa en effet, dans ses articles d'Al-Churûq, à dicter, point par point, des recommandations au Conseil militaire pour le guider dans le processus de la transition politique. Il agit de même à l'endroit du ministère de l'Intérieur pour remédier au vide sécuritaire dont souffrait la société égyptienne et prodigua des conseils aux candidats engagés dans la course aux élections ${ }^{29}$. Ainsi, en mettant en avant sa qualité d'expert en politique, Hamzâwî suggérait que son savoir sur la transition démocratique lui fournissait la légitimité nécessaire pour conduire, lui-même, ladite transition.

Puisque le savoir et la science prétendent à l'impartialité, l'identité de l'universitaire a également permis à Hamzâwî à construire l'illusion de l'objectivité et de la prise de distance à l'égard du jeu politique. En tant qu'expert en science politique, Hamzâwî a commenté les tractations menées par les autres candidats comme s'il se situait à l'extérieur du champ politique. Ainsi, il adressa des critiques aux candidats coupables de ne pas suffisamment exposer leurs options politiques à l'opinion publique, de passer d'un parti à l'autre ou de se présenter aux élections à titre individuel ${ }^{30}$, critiques auxquelles il opposait sa propre confession sur les raisons qui l'avaient poussé à quitter le parti Égyptien Démocratique et Socialiste, à adhérer à la liste du Bloc Égyptien et à s'en retirer ensuite, à créer son propre parti politique - l'Égypte de la liberté - mais à se présenter, en fin de compte, à titre individuel aux élections ${ }^{31}$. Ses critiques à l'égard de l'élite politique égyptienne, "manquant de professionnalisme» et "incapable de travailler en équipe ", s'inscrivaient dans la même veine, de même que celle de «l'étroitesse de la vision» des acteurs politiques dans leur poursuite d'intérêts particuliers en lieu et place de l'intérêt général ${ }^{32}$. Même dans les yawmiyât (le journal quotidien) qu'il lança à l'occasion de l'ouverture de sa campagne électorale et dont le but était de "sauver l'universitaire, de maintenir la rationalité de la réflexion et la capacité à faire son autocritique ", Hamzâwî s'attacha à dénoncer le caractère non démocratique des pratiques électorales déployées par ses rivaux ${ }^{33}$. Enfin, l'identité de savant lui servit de refuge lorsque la tension entre sa figure d'homme politique et celle d'universitaire devenait insurmontable. À plusieurs reprises, Hamzâwî exprima la difficulté de concilier les deux aspects de son identité. À la différence d'un intellectuel, qui doit faire preuve de liberté de pensée et de désintéressement, la liberté de l'homme politique est restreinte par les attentes de sa base électorale. Le lancement des yawmiyât dans Al-Churûq fut précisément une tentative pour concilier ces deux identités en portant un regard réflexif sur le déroulement de sa campagne. Cependant, lorsque Hamzâwî était exposé à la critique à cause de ses prises de position, il se réfugiait dans l'identité de l'intellectuel en invoquant la liberté individuelle. Ainsi, dans sa réponse à une attaque lancée par son propre camp en réaction à sa participation à l'émission salafiste de Khâlid Abdallah, il confia: "Dans ces moments, je reviens à ma vie 
antérieure, à la vie d'un universitaire, d'un chercheur et d'un écrivain, qui corrige et précise ses idées en toute liberté, sans être sujet à des pratiques dictatoriales qui visent à le faire taire ou à l'interdire. Devant moi, le chemin est encore long pour m'habituer à la vie politique et, peut être ne m'y habituerai-je jamais ${ }^{34}$ ».

Il faut noter, cependant, que le recours à la légitimité universitaire dans le combat politique était probablement une conduite inconsciente, imputable à sa double identité d'intellectuel et d'homme politique, et aux tensions qu'elle générait. Camoufler les armes du combat politique en instruments d'analyse est une conduite, si l'on en croit Pierre Bourdieu, propre au champ intellectuel et scientifique ${ }^{35}$, qui se fonde sur un type spécifique de légitimité dont jouissent les intellectuels, en particulier dans les cultures où ils continuent de bénéficier d'un grand prestige social. Le capital universitaire dont sont gratifiés les universitaires leur permet d'user de la force symbolique de la science pour se poser en juge du jeu politique. Toutefois, au cours de sa carrière politique, Hamzâwî semble avoir assumé de plus en plus son identité de professionnel du politique au détriment de la figure de «l'intellectuel libre » qu'il incarnait auparavant. Si Hamzâwî s'était distingué comme un défenseur de la doctrine du libéralisme, prêt à défier les conventions sociales, son engagement dans le jeu politique institutionnel a eu pour résultat un certain infléchissement de sa radicalité initiale. L'événement marquant fut sa participation à l'émission salafiste Misr Jadîda, évoquée précédemment, qui fut une véritable onde du choc dans les milieux libéraux. Si son consentement à participer à une émission opposée aux libéraux était manifestement un acte de courage, ses prises de positions contre le mariage civil dont il était, auparavant, le défenseur ${ }^{36}$, de même que sa promesse de respecter la loi islamique dans la législation, ont été perçues comme une compromission avec les courants islamistes. Aux accusations qui ont suivi l'émission, Hamzâwî a répondu par deux articles où il a défendu ses positions comme conformes à l'essence du libéralisme tout en accusant ses critiques d'ignorance, leur reprochant de se comporter comme les islamistes qui refusent le dialogue ${ }^{37}$. L'investissement de Hamzâwî dans une identité politique était manifeste dans l'argumentaire avancé pour justifier son renoncement à défendre les principes contraires à la loi islamique. Il invoquait, à cet égard, sa vocation à représenter l'ensemble des Égyptien en sa qualité de député, et la responsabilité politique qui en découlait : "À un aucun moment, ni lors d'une aucune rencontre, je n'ai appelé à des pratiques contredisant la loi islamique. Je n'y ai pas appelé et je les refuse d'une manière claire, comme les refuse toute personne raisonnée en Égypte, surtout si cette personne raisonnée veut pratiquer la politique, parce qu'elle connaît l'importance de la loi islamique et de ses principes pour les Égyptiens ${ }^{38}$ ». En énonçant son refus de défendre des principes qui vont à l'encontre des valeurs des Égyptiens, au motif qu'il est appelé, en tant que député au Parlement, à tous les représenter, Hamzâwî s'éloigne de sa figure d'intellectuel libre, prêt à défier les traditions, et s'approche de celle d'un homme politique, appelé à modérer ses perspectives pour élargir sa base électorale.

\section{Conclusion}

En période électorale, une des qualités essentielles des candidats est leur capacité à être connu et reconnu par les électeurs. À cet égard, les médias, aussi bien les chaînes télévisées que la presse dite indépendante, se sont révélés des vecteurs incontournables 
pour faire connaître les nouvelles personnalités sur la scène politique bouillonnante de l'après Moubarak. En fournissant l'accès à leurs plateaux télévisés à certaines personnalités, les chaînes télévisées ont contribué à accroître leur visibilité et leur influence auprès du public en contribuant ainsi à l'investiture des candidats. La peoplisation de la compétition électorale que suggère l'examen de la campagne de Hamzâwî pourrait bien constituer un trait constant des élections à venir, compte tenu du rôle grandissant que jouent les médias sur la scène politique. L'importance du facteur médiatique dans les élections réside dans le fait qu'il contribue à marginaliser, ne fut-ce que dans certaines circonscriptions électorales comme Héliopolis, le facteur de la notabilité locale qui est le principe traditionnel de la légitimité électorale. Cela a permis à Hamzâwî d'organiser sa campagne électorale sur le terrain autour du thème de la rupture d'avec les pratiques corrompues héritées de l'ancien régime, et de se forger l'image d'un initiateur de pratiques purement démocratiques.

Cette figure a été appuyée par son identité d'universitaire armé de savoir et de compétence pour mener à bien la transition démocratique. Le prestige scientifique dont jouissait Hamzâwî a été d'autant plus puissant qu'il a été acquis en Occident, ce qui constitue, certes, un sérieux handicap lorsque le soupçon est de mise, mais confère également une certaine autorité à son détenteur, fondée sur l'idée de la qualité de l'enseignement et de la recherche scientifique en Europe. Si sa double identité d'homme politique et d'universitaire était une source de tensions et de contradictions, elle lui a apporté un certain avantage : elle lui a permis d'alterner ses positionnements par rapport au champ politique, et d'agir en universitaire, situé en dehors du champ politique, quand il s'agissait de commenter et d'évaluer le jeu politique, mais aussi de se transformer en homme politique, appelé à représenter la nation au Parlement. Dans la mesure où les champs intellectuel et académique se parent des apparences de la liberté d'expression et de pensée, ils sont moins sujets au discrédit que le champ politique, par définition corrompu et corrupteur. Cette double identité d'universitaire et d'homme politique en rejoint une autre, non dépourvue, elle aussi, de tensions internes : celle du révolutionnaire-député au Parlement, que Hamzâwî a dû assumer après sa victoire électorale. Dans le contexte où s'affrontent deux types de légitimité, celle de Tahrîr et celle du Parlement, que peut devenir un révolutionnaire élu au Parlement ? C'est cette difficulté à concilier ces deux types de légitimité qui explique les atermoiements du discours de 'Amr Hamzâwî.

\section{BIBLIOGRAPHIE}

BEN NEFISSA S. \& ALÂ' AL-DÎN A., 2005, Vote et démocratie dans l'Égypte contemporaine, Paris, IRDKarthala.

Bourdieu P., Homo Academicus, Paris, Éditions de Minuit, 1984.

- 2001, Langage et pouvoir symbolique, Paris, Seuil. 
Dessouki N. H., 2011, « Représentations du rôle du député chez les électeurs égyptiens : le cas des circonscriptions 24 et 25 de Hélouane ", Égypte/Monde arabe, vol. 3, n 7, p. 47-67.

Kepel G. \& Richard Y. (dir.), 1990, Intellectuels et militants de l'islam contemporain, Paris, Seuil.

Klaus E., 2011, « Les journalistes face à la révolution. L'histoire de la presse égyptienne », La Vie des Idées, http://www.laviedesidees.fr/Les-journalistes-face-aux.html?lang=fr, consulté en février 2012.

\section{NOTES}

1. Neveu du président assassiné Anouar Al-Sadate, Tal'at Al-Sâdât a été membre du Parlement en 2005-2010. Après le départ de Hosni Moubarak, il a assuré la direction du parti National Démocratique en espérant le réformer, mais le parti a été dissous peu après. Ensuite, il a fondé son propre parti, le parti National Égyptien. Il est brutalement décédé en en novembre 2011, juste après le lancement de sa campagne électorale.

2. Enrique Klaus, «Les journalistes face à la révolution. L'histoire de la presse égyptienne ", La Vie des Idées, 21 octobre 2011, http://www.laviedesidees.fr/Lesjournalistes-face-aux.html?lang=fr (accédé en février 2012).

3. À titre d'exemple, une discussion sur «L'Avenir des médias en Égypte » diffusée dans un débat télévisé «Le dernier mot» (âkhir kalâm) en mai 2011 sur ONTV: http:// www.youtube.com/watch?v=fs5Z_MZ0Lms (accédé en février 2012). L'indépendance et le caractère révolutionnaire des chaînes privées sont discutables. Chaque chaîne privée a sa propre sensibilité vis-à-vis d'un mouvement de contestation lui-même hétérogène, et rares sont celles qui osent ouvrir le débat sur des questions impliquant les activités de l'armée. La liberté des animateurs des talk-shows est toujours soumise à des restrictions, comme en témoigne la suspension de l'émission âkhir kalâm par son animateur Yusrî Fûda en signe de protestation contre la censure, et le licenciement de Dîna 'Abd Al-Rahmân après ses critiques adressées au CSFA. L'appartenance des chaînes privées aux hommes d'affaires enrichis sous le régime de Moubarak, et dont certains, à l'instar de Nagîb Sâwîris, ont un agenda politique, font que l'indépendance des chaînes privées demeure très relative.

4. À partir du mois de septembre 2011, le CSFA a gelé l'octroi de nouvelles licences à des chaînes privées.

5. Un exemple significatif de la récupération médiatique des figures associées à la contestation puis de leur conversion en « leaders de la révolution » est offert par le cas de « l'imâm révolutionnaire » Mazhar Châhîn. Imâm de la mosquée stratégique d'Omar Makram, située à Tahrîr et transformée en hôpital improvisé lors des affrontements, Mazhar Châhîn s'est illustré par ses sermons du vendredi prononcés directement sur la place. En septembre 2011, Mazhar Châhîn est invité par la chaîne $C B C$ pour animer un talk-show « Des Gens et des gens » (Nâs wa Nâs).

6. Fathî Abû Hatab, manager des communautés en ligne d'Al-Masrî Al-Yawm, cité par H. Klaus, op cit.

7. Cette observation repose sur l'examen des auteurs d'articles d'opinion parus dans AlChurûq entre le 11 février 2011 et 30 mars 2011.

8. À ce titre, on peut évoquer les exemples de 'Alî Al-Silmî, ancien vice-Premier ministre dans le second cabinet de 'Isâm Charaf (3 mars-21 novembre 2011), et de 'Imâd 
Abû Ghâzî, directeur du Conseil supérieur de la Culture à l'époque de Moubarak et ministre de la Culture dans le cabinet de 'Isâm Charaf jusqu'à sa démission le 20 novembre 2011. 'Alî Al-Silmî, auteur d'un « document constitutionnel » controversé qui immunisait l'armée contre le contrôle parlementaire, a commencé à écrire dans AlMasrî Al-Yawm à partir du 27 décembre 2011, après avoir quitté son poste de vicePremier ministre. Quant à 'Imâd Abû Ghâzî, contesté dans les milieux de la culture à cause de sa proximité avec l'ancien régime, ses articles paraissent dans Al-Churûq à partir de janvier 2012.

9. A. Mûsâ, « Secrets de l'ouverture des négociations entre les États-Unis et les Frères musulmans" (Asrâr fath hiwâr bayn al-wilayât al-mutahida wa gamâ'at Al-Ikhwân), AlAhrâm, 14 avril 2007, http://www.ahram.org.eg/Archive/2007/4/14/INVE11.HTM (accédé en février 2012).

10. Mustafa Ragab, «L'Allemand 'Amr suit Sa'd Al-Dîn Ibrahîm » (Rûz Al-Yûsif, 21-27 avril 2007. Sa'd Al-Dîn Ibrahîm est le fondateur du Centre d'études Ibn Khaldûn sur le développement (ICDS) ainsi que de l'Organisation Arabe pour les droits humains (AOHR). Accusé d'être à la solde de l'Occident en raison du recours d'ICDS à des fonds américains, Sa'd Al-Dîn Ibrahîm a été condamné à deux ans de prison pour avoir « insulté l'Égypte ».

11. S. Ahmad Salâma, "Amr Hamzâwî et la sécurité " ('Amr Hamzâwî wal-amn), Huriyitnâ, 9 mai 2007, http://www.horytna.net/Articles/Details.aspx?AID=450 (accédé en février 2012).

12. Parmi ces initiatives, on peut mentionner la création, le 4 février 2011, du Conseil des sages de la révolution (lajnat hukamâ' Al-Thawra) dont 'Amr Hamzâwî fut le porteparole. Soupçonné de vouloir s'imposer aux manifestants de Tahrîr, le Conseil se dissout le 8 février après la publication de quatre communiqués adressés au CSFA.

13. A. Hamzâwî, «Je doute » (achuk), Al-Churûq, 18 août 2011, http:// www.shorouknews.com/columns/view.aspx?

cdate=18082011\&id=1ac8b95a-7917-4fa7-9c96-a57a69b60cb2 (accédé en février 2012).

14. On pourrait citer en exemple une chanson rap intitulée "Je doute" (achuk), composée par le rappeur égyptien 7orus, dans laquelle il prend la défense de Hamzâwî http://www.youtube.com/watch?v=bInvoyQDo7Y\&fb_source=message (accédé en mars 2012).

15. Néfissa Hassan Dessouki, «Représentations du rôle du député chez les électeurs égyptiens : le cas des circonscriptions 24 et 25 de Hélouane », dans Florian Kohstall et Frédéric Vairel (dir.) « Fabrique des élections », Égypte/Monde arabe, vol. 3, n 7, 2011.

16. Sarah Ben Nefissa et Alâ' Al-dîn Arafat, Vote et démocratie dans l'Égypte contemporaine, Paris, IRD-Karthala, 2005.

17. Propos tenus lors de sa conférence organisée dans le cadre de sa campagne électorale à l'hôtel Sonesta, Héliopolis, novembre 2011.

18. A. Hamzâwî, « Sur ce qui se passe sur la scène politique » (Ba'd ma yadûr fi-l-sahât alsiyâsiyya), Al-Churûq, 25 octobre 2011.

19. Conférence de presse donnée à l'occasion du lancement de son programme électoral intitulé "La circonscription, l'exemple pour le pays", tenue le 13 novembre 2011. Hamzâwî a amorcé la mise en œuvre de ces projets en rendant visite, le 11 janvier 2012, au maire du Caire, 'Abd Al-Qawî Khalîfa. 
20. Cet engagement a été compromis par ses propres volontaires, qui ont collé des affiches de Hamzâwî au dessus de celles du candidat rival Muhammad Sa'd Abû Al'Azm. Hamzâwî s'est vu contraint de lui présenter ses excuses officielles.

21. Par exemple, A. Hamzâwî, « Aux chrétiens d'Égypte » (Ilâ masîhiyî misr), Al-Churûq, 8 mars 2011, «Le droit à la patrie des chrétiens et des musulmans » (Haq al-watan bîmasîhiyîha wa-muslimîha), Al-Churûq, 12 octobre 2011.

22. Plusieurs électeurs rencontrés à Héliopolis étaient convaincus à tort que Hamzâwî était le candidat du parti des Égyptien Libres de Nagîb Sâwîris.

23. Khawâga est un des termes employés pour désigner « l'étranger » en Égypte. Sur « le complexe du Khawâga» dans les milieux intellectuels égyptiens, voir A. Roussillon, "Intellectuels en crise dans l'Égypte contemporaine ", dans Gilles Kepel et Yann Richard (dir.), Intellectuels et militants de l'islam contemporain, Paris, Seuil, 1990.

24. Conférence publique de 'Amr Hamzâwî à l'hôtel Sonesta, 13 novembre 2011.

25. A. Hamzâwî, « Les défauts de la politique et des médias. La drame de la tromperie et de la surenchère" (Nawâqis al-siyâsa wal -i'lâm. Ma'asât al-tahâyul wal-muzâyada), AlChurûq, 26 septembre 2011.

26. A. Hamzâwî, « La Monopolisation de la révolution » (Ihtikâr al-thawra), Al-Churûq, 19 juillet 2011.

27. Le président du parti National Égyptien, Tal'at Al-Sâdât, demanda le 15 novembre 2011 d'interdire aux porteurs d'une double nationalité de se présenter aux élections.

28. Pierre Bourdieu, Langage et pouvoir symbolique, Paris, Seuil, 2001, p. 331-377.

29. Voir respectivement les articles publiés dans Al-Churûq par Hamzâwî, «Les Affaires de la transition démocratique " (Chu'ûn al-tahawul al-dîmuqrâtî), 20 juillet 2011, «La crise sécuritaire... État de lieux et recommandations " (Al-Azma al-amniya... tawsîf watawsiyât), 14 septembre 2011, "Quelques maladies de l'élite politique » (Ba'd amrâd alnukhba al-siyâsiyya), 21 octobre 2011.

30. A. Hamzâwî, « Quelques remarques sur les partis et les candidats qui se présentent à titre individuel » (Ba'ad mulâhazât al-ahzâb wal-murachahîn 'alâ al-maqấ'id al-fardiyya), AlChurûq, 17 octobre 2011.

31. A. Hamzâwî, «La remise au point de l'auto-évaluation politique » (I'âdat al-zabt biwasla al-zât al-siyâsiyya), 2 parties, Al-Churûq, 19 et 20 octobre 2011. Il convient de noter, en passant, que les tergiversations des partis politiques avant les élections ont été dues à l'environnement légal changeant et indécis, et que les acteurs politiques ont opéré leurs choix en fonction des chances que l'environnement légal leur offrait de remporter les élections.

32. A. Hamzâwî, "Quelques maladies de l'élite politique " ( $B a^{\prime} d$ amrâd al-nukhba alsiyâsiyya), Al-Churûq, 21 octobre 2011; "Le jeu politique » (Al-Lu'ba al-siyâsiyya), AlChurûq, 16 octobre 2011.

33. A. Hamzâwî, «Les élections parlementaires 2011 et le journal quotidien d'un candidat universitaire " (Intikhâbât barlamâniyya 2011 wa-yawmiyât murachah akâdîmî), Al-Churûq, 10 novembre 2011.

34. A. Hamzâwî, «La Dictature au nom du libéralisme » (Diktâtûriyya bi-ism librâlîyya), Al-Churûq, 18 janvier 2012.

35. P. Bourdieu, Homo Academicus, Paris, Éditions de Minuit, 1984. 
36. Dans un talk-show «Al-Qâhira Al-Yawm » (Le Caire Aujourd'hui) diffusé en mai 2011, Hamzâwî s'était prononcé en faveur du mariage civil. En novembre, Hamzâwî réapparaissait dans la même émission pour clarifier sa position en expliquant qu'il ne défendait le droit au mariage civil que pour les cas suivants: le mariage entre un Égyptien et une femme étrangère et le cas du deuxième mariage des femmes chrétiennes. Les extraits des émissions sont sur Youtube: http://www.youtube.com/ watch?v=EUl4lghEZRI et http://www.youtube.com/watch?v=I_7cjVbB1IU\&sns=em (accédé en février 2012).

37. A. Hamzâwî, «La Dictature au nom du libéralisme ", op. cit.; "Les Libéraux dans leurs demeures " (Lîbrâliyyîn fî manâzilihim), Al-Churûq, 22 janvier 2012.

38. 'Amr Hamzâwî dans un talk-show « Misr Jadîda » (La Nouvelle Égypte), diffusé sur la chaîne de tendance salafiste Al-Nâs en janvier 2011.

\section{RÉSUMÉS}

Le présent article est consacré à l'étude de la campagne électorale organisée par 'Amr Hamzâwî, chercheur et professeur en science politique, dans le cadre de sa candidature aux élections législatives tenues en Égypte en novembre 2011. Libéral occidentalisé, détenteur d'une double nationalité, résidant de longue date à l'étranger, dépourvu d'appuis locaux et d'expérience politique en Égypte, 'Amr Hamzâwî réunissait des attributs disqualifiants dans le jeu politique égyptien. À partir de l'étude ethnographique de sa campagne à Héliopolis, de ses discours publics et articles parus dans la presse égyptienne, cet article vise à mettre à jour les différents répertoires de mobilisation électorale du candidat Hamzâwî.

The present study examines the electoral strategies employed by Egyptian academic and political scientist 'Amr Hamzâwî in the last parliamentary elections held in Egypt fall 2011. As a liberal intellectual linked to a foreign think-tank and largely devoid of previous political experience and therefore lacking significant local support in his constituency, Hamzâwî presented a number of disqualifying conditions for a traditional electoral game in Egypt. Based on his public speeches, talk shows, articles as well as on an ethnographic research of his electoral campaign launched in Heliopolis, this paper seeks to explore the argumentative strategies employed by Hamzâwî to transform the flaws of his candidacy into powerful assets in the electoral competition.

\section{INDEX}

Keywords : Hamzâwî, Elections, Intellectuals, Medias, Liberal

Mots-clés : Hamzâwî, élections, intellectuels, médias, libéral 


\section{AUTEUR}

\section{GIEDRE SABASEVICIUTE}

Giedre Sabaseviciute est doctorante en sociologie à l'École des hautes études en sciences sociales à Paris, associée au CEDEJ depuis 2011. Elle est en train de mener une thèse sur les intellectuels égyptiens lors du coup d'État de 1952.

Giedre Sabaseviciute is a PhD candidate in the field of sociology at the École des Hautes Études en Sciences Sociales in Paris. She is also an associate researcher at CEDEJ since 2011. Her PhD thesis concerns the Egyptian intellectuals during the 1952 coup. 